\section{Nine Pints: a Journey Through the Mysterious, Miraculous World of Blood Rose George}

Portobello Books, 2019, PB, 384pp, E8.56, 978-1846276125

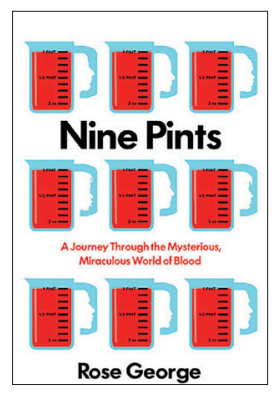

\section{OUT FOR BLOOD}

This is a fascinating account of the mysterious red substance that flows around all our bodies. Divided into nine chapters to represent the nine pints in the average human body, it cover topics as diverse as the origins of the blood transfusion service, HIV in South Africa, menstrual taboos, and the management of major trauma. The author, Rose George, is an investigative journalist and she creates a compelling narrative suitable for both lay readers and healthcare professionals. Historical details about the discovery of circulatory system, early attempts at blood transfusion, and blood-letting treatments are cleverly interwoven with current research.

I was intrigued and a little revolted to read about her visit to a leech farm in Wales where tanks are designed to give the leeches the optimum amount of exercise. They are then starved for 6 months, sterilised by UV light, before being dispatched by post. Leeches are used mainly following plastic surgery to remove blood from engorged grafts where the capillary network has yet to recover.

Nine Pints is not always an easy read. I was disturbed to learn about the continued use of paid plasma donors by commercial companies in Canada and the privatisation of the UK plasma supply industry, and I was saddened to read of the large number of Nepalese women who are still subject to freedom-limiting menstrual taboos including having to sleep outside or stay in a crude hut when menstruating.

I appreciated her righteous anger about girls not attending school because of the lack of sanitary provision in many developing countries and young women receiving so-called 'blessings' Iwhich might include lunch money, phone credit, or hair weaves in return for sex with older men in South Africa), which is fuelling the HIV epidemic. Then there are the lost generation of haemophiliacs in the UK who contracted blood-borne viruses from Factor VIII (contaminated with HIV and/or hepatitis C during the 1970s and 1980s) and who have yet to receive an apology from the government.

She introduces unsung heroes such as Janet Vaughan, who established the UK blood transfusion service, and Arunachalam Muruganantham, who developed a machine that can manufacture sanitary pads very cheaply and has provided employment in resource-poor settings.

The final chapter gives a brief history of vampires including a US company called 'Ambrosia', which offers to reverse the ageing process by transfusing its customers with blood from young donors. It concludes with a discussion of the latest efforts to develop an artificial blood substitute.

There are occasional jarring elements: the author asserts that her own endometriosis was caused by exposure to environmental toxins, despite quoting research studies that fail to support her point of view, and when commenting on people with HIV being jailed for not disclosing their status to their partners she states that: 'Chlamydia and hepatitis, now more life threatening or disabling, get no such sanction.

The US spellings used throughout the book are a little incongruous in a book dedicated to the NHS.

Overall, though, this was an entertaining and thought-provoking read, and I was left feeling grateful to live in a developed country with accessible treatment for blood-borne viruses, sanitary provision available to all, and for our blood transfusion service supported by altruistic donors.

\section{Katharine Margaret Bradbury,}

GP Partner, Hucknall Road Medical Centre, Nottingham.

Email: katharine.bradburylanhs.net

DOI: https://doi.org/10.3399/bjgp20X709181

\section{Waking Up: Searching for Spirituality Without Religion \\ Sam Harris}

Black Swan, 2015, PB, 256pp, E9.99, 978-

1784160029

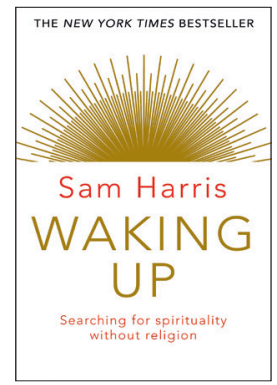

\section{ONLY THE SPIRIT?}

Sam Harris captures a popular call for spirituality that is good for mental health and not tainted by religion. He expands the secular concept of spirituality fruitfully, but his insights are limited by a lack of academic rigour or practitioner experience.

Harris argues that spirituality is not only an indispensable part of understanding the nature of the mind' but also requires a broader focus than the individual. Spirituality has ethical and relational aspects distinguishing it from concepts of individual mental wellness or peace. This is an important insight: the need to think about spirituality in a more communal way.

Harris's propositions are informed by neuroscience, Buddhist teachings, and personal experiences of psychotropic drugs. He dismisses religious traditions, including contemplative traditions, even though they may have much in common with what he regards as spiritual. Harris is upfront about this, but this suggests an ideological position rather than a genuine enquiry. Harris creates an account of spirituality later in the book that is primarily neurological, calling on functional MRI and other evidence. Extensive notes and references are provided but these omit mainstream academic work on spirituality and health/mental health, for example, that of Chris Cook, John Swinton, or Harold Koenig, which would provide balance to Harris's arguments, or in some cases challenge them.

Those looking for help with spiritual practices will find brief advice on dealing with negative emotions, but Harris strays readily into bizarre-sounding meditations, including imagining one has no head! Harris not only references mindfulness- 
informed techniques that have empirical support but also recommends using recreational drugs to create spiritual awareness, despite evidence that this can lead to poor psychological outcomes.

It is informative that Harris, a committed atheist, joins this debate and comes down on the side of spirituality as a crucial concept that relates to mental health, with implications for medical practice. He usefully expands this concept beyond the individual. He captures the zeitgeist of 'religion-free spirituality' but at a cost: academically robust accounts of spirituality and mental wellness deserve to be empirically and philosophically constructed without first ring-fencing the enquiry in this way.

\section{Alistair Appleby,}

General Practitioner \& Senior Clinical Lecturer, Aviemore.

Email: alistairappleby2đagmail.com

DOl: https://doi.org/10.3399/bjgp20X709193

$$
* * * * *
$$

\section{Polio: the Odyssey of Eradication Thomas Abraham}

C Hurst \& Co Publishers Ltd, 2018, HB, 320pp, E19.26, 978-1849049566

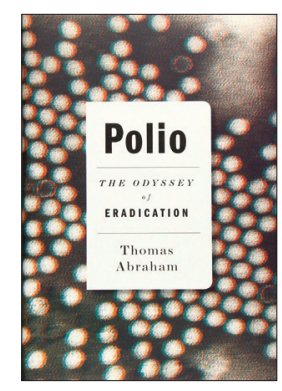

\section{A WORLD FREE OF POLIO?}

Polio: the Odyssey of Eradication is a fascinating book providing an insight into how polio became the second disease (after smallpox) to be targeted for global eradication, and why, after a multi-billion dollar vaccination campaign spanning 31 years, polio still causes a small number of cases each year.

The book is written by Thomas Abraham, a journalist, who delves into the politics behind why polio was chosen for eradication over the likes of measles and diphtheria, how the Salk and Sabin vaccines were developed (with some questionable ethics along the wayl, and how the Rotary
Association came to be one of the biggest funders of polio vaccination globally.

After Franklin D Roosevelt was struck down by a paralytic illness in 1921 lthought to be polio at the time, but probably Guillain-Barré syndrome) and outbreaks swept across the US in the 1950s, Americans were on a mission to eradicate polio, erroneously assuming that the rest of the world felt the same way.

In 2019, there are a small number of polio cases each year, mainly in Pakistan, Afghanistan, and Nigeria, and the deadline for eradication is being pushed back each year. Abraham chronicles some of the reasons for this ongoing failure including targeted killings of polio vaccinators by the Taliban, loss of confidence after a plot by the CIA to use vaccines to find Osama Bin Laden, and myths about the vaccine being used to sterilise populations. Additionally, the live vaccine has been causing outbreaks, and the goal of eradication remains elusive.

This book will be of interest to GPs, especially those with an interest in global and public health. Just because a disease potentially can be eradicated, does it mean we should try? The answer is much more nuanced than one might expect.

\section{Sophie Rowlands,}

GP, Coachmans Medical Practice, West Sussex; also part of the Education and Training Team, RCGP JIC.

Email: drsophierowlandsđagmail.com

DOI: https://doi.org/10.3399/bjgp20X709205

\section{Laugh out Dead: an Urban-Smith Mystery Rupert Harker}

The Blue Belvoir, 2018, PB, 299pp, E7.99, 978-1913006013

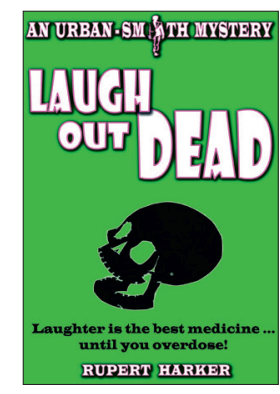

\section{SUPERNATURAL MIRTH}

Laugh out Dead is an interesting title that caught my attention. Following his interest in pathology as a medical student, Rupert Harker was inspired to write this book by watching classic Sherlock Holmes. It is the first book in a self-published UrbanSmith Mystery series. The main character is the curiously named forensic pathologist Rupert Harker, who meets a paranormal detective, Fairfax Urban-Smith, when he enters the mortuary, disturbing the postmortem that Rupert is conducting. Fairfax eloquently and effortlessly deduces the sorry soul's untimely end with perfect precision. And there the story begins.

Rupert and Fairfax form an unlikely partnership. Fairfax, a renowned criminal investigator of supernatural phenomena, (a 'paranorensicologist'), introduces Rupert to concepts such as 'sensitives' and 'vibrations'. Rupert is sceptical. However, when more than one high-profile Russian scientist dies by apparently laughing to death, the pathological evidence suggests that they may be connected. The cases incorporate paramilitaries, ex-KGB scientists, assassins, and some cheeky innuendo references. Rupert gets a share of romance with the lovely Nell, which, in turn, leads the story towards a new avenue of events.

During an interview for the book, the ice-cream-eating author describes a difficult period in his life where he required psychological intervention. Encouraged by his therapist, the author commands respect for demonstrating hope and opportunity even when battling with mental health issues. I enjoyed learning terms such as papamorsuphobia la fear of being bitten by the pope) and lingotelepathy (the ability to communicate with trees).

Using anatomical, pathological, and some physiological descriptions, the author weaves elements of Sherlock Holmes with medicine, the paranormal, and physics. I enjoyed reading this light-hearted and witty book, and learned some new terms too.

\section{Bernadeta Bridgwood,}

GP, Hannage Brook Medical Centre, Derbyshire.

\section{Email: exchangejicðagmail.com}

The complete trilogy of the series is now available: http://r-harker.com/books/

DOI: https://doi.org/10.3399/bjgp20X709301 